\section{Toward an adequate understanding of attention deficit disorders}

\author{
Rumo à compreensão \\ adequada das doenças \\ do déficit de atenção
}

Throughout the world, the syndrome identified in DSM-IV as Attention Deficit/Hyperactivity Disorder (ADD) is being increasingly diagnosed in children, adolescents and adults, most of whom find treatment quite helpful.

Yet many clinicians and others remain skeptical about the validity of this diagnosis, particularly in adults. For some, this skepticism rests upon an overly simplistic understanding of the ADD syndrome; they assume that this is simply a childhood behavior disorder that persists in some adults who remain hyperactive.

Barkley \& Murphy recently published data showing that adults with ADD are distinguished from community or clinical controls not by hyperactivity, but by a variety of impairments in executive functions. ${ }^{1}$ Although there are conflicting views of how best to describe the relationship of executive functions to ADD, data from multiple sources indicate that ADD is essentially a complex syndrome of impairments in development of the brain's selfmanagement systems. ${ }^{2}$

Key elements of this emerging model include:

1) ADD is essentially a complex disorder in the unfolding development of the brain's executive functions, its management systems.

Although early decades of research on ADD were concerned with disruptive behavior, recent years have brought increasing emphasis upon cognitive impairments involved in this disorder. These include chronic problems with focusing attention on tasks, utilizing working memory, organizing work, getting started on tasks, and sustaining effort to complete them in a timely way, etc.

These cognitive functions might be compared to the work of the conductor of a symphony orchestra who selects what is to be played, directs each musician to play his or her specific part in the same piece at the same, signals the moment to bring in one section and fade out another, and generally oversees and manages the overall performance. Persons with ADD tend to have chronic impairments in their ability to perform a wide range of complex self-management functions that are essential to age-appropriate performance in school, family life, employment and social relationships. ${ }^{3}$

2) ADD symptoms may be noticeable during early childhood, but often are not apparent until the individual encounters challenges of adolescence or adulthood.

Networks that support the brain's executive functions develop slowly, from early childhood until well into the early twenties. Many are localized in the prefrontal cortex, but they operate in conjunction with neural circuits in the limbic region and cerebellum. These complex circuits do not reach full maturity until late adolescence or early adulthood.

Some cases of ADD impairment are apparent in preschool years, for example, the child who is kicked out of daycare because of inability to meet minimal demands for self-regulation: keeping hands to self, complying with instructions, listening to the adults. 
Others with ADD may function well in early school years; their impairments may not become apparent until their capacity for executive functions is more fully challenged, e.g. in secondary school when they no longer have one teacher most of the day to guide them and when they must manage for themselves multiple tasks from multiple teachers.

3) ADD appears to be a problem of insufficient willpower, but it is actually a problem in the chemical dynamics of the brain.

Many who know individuals with ADD are puzzled by the fact that all seem able to focus very well for a few selected tasks in which they have strong personal interest, e.g. playing a sport or video game, doing mechanical work, or creating art or music. Yet these same individuals have chronic difficulty in exercising executive functions required for focus on many other necessary daily tasks of school, household, or employment.

When asked about this puzzling discrepancy, most with ADD explain that they can focus well on tasks that really interest them, or when a gun is to their head, yet they are chronically unable to get themselves to exercise these same functions for many other tasks important to them in daily life. For example, they tend repeatedly to avoid starting an assignment until very shortly before its final deadline.

Such patterns of behavior might be seen simply as laziness or lack of willpower, but research has demonstrated that there is a chemistry to motivation. In about $80 \%$ of those with ADD such problems are alleviated by medication treatments that facilitate more adequate release and reloading of dopamine and/or norepinephrine in critical neural synapses. ${ }^{3}$

Medication-induced alleviation of ADD symptoms is always temporary, persisting only so long as the medication is active; this is comparable to eyeglasses that improve impaired vision only when worn. But medication is the single treatment demonstrated effective for alleviating impairments in the neural substrate that supports executive functions impaired in ADD. ${ }^{4}$

The more complex model of ADD discussed here describes a syndrome that is important not only in itself, but also because it tends to occur in conjunction with many other psychiatric disorders. In most cases, ADD onsets much earlier than mood disorders, anxiety disorders, substance use disorders, etc. Noting this, Kessler et al. have questioned whether effective treatment of ADD in childhood might influence the onset of subsequent disorders, and whether treatment of ADD in adults might have any effect on the severity or persistence of comorbid disorders. ${ }^{5}$ To address these important questions adequately, clinicians and researchers need to appreciate and study the complexity of ADD across the lifespan.

Thomas E Brown Yale Clinic for Attention and Related Disorders, Department. of Psychiatry, Yale University School of Medicine, New Haven, CT, USA

\section{References}

1. Barkley RA, Murphy KR. Identifying new symptoms for diagnosing ADHD in adulthood. ADHD Report. 2006;14(4):7-11.

2. Brown TE. Executive functions and attention deficit hyperactivity disorder: implications of two conflicting views. Int J Disab Develop Edu. 2006;53(1):35-46.

3. Brown TE. Attention deficit disorder: the unfocused mind in children and adults. New Haven, CT: Yale University Press; 2005.

4. Barkley RA. Attention-deficit hyperactivity disorder: a handbook for diagnosis and treatment. 3rd ed. New York: Guilford Press; 2006.

5. Kessler RC, Adler L, Barkley R, Biederman J, Conners CK, Demler O, Faraone SV, Greenhill LL, Howes MJ, Secnik K, Spencer T, Ustun TB, Walters EE, Zaslavsky AM. The prevalence and correlates of adult ADHD in the United States: results from the National Comorbidity Survey Replication. Am J Psychiatry. 2006;163(4):716-23. 